OPEN ACCESS

Edited by:

Laure Cauchard,

University of Aberdeen,

United Kingdom

Reviewed by:

Matthew Louder,

The University of Tokyo, Japan

Alex Kacelnik,

University of Oxford, United Kingdom Vanina Dafne Fiorini,

University of Buenos Aires, Argentina

${ }^{*}$ Correspondence:

David J. White

dwhite@wlu.ca

Specialty section:

This article was submitted to Behavioral and Evolutionary Ecology,

a section of the journal

Frontiers in Ecology and Evolution

Received: 01 February 2020

Accepted: 02 June 2020

Published: 26 June 2020

Citation:

White DJ (2020) Avian Egg

Timers: Female Cowbirds Judge Past,

Present, and Future When Making

Nest Parasitism Decisions.

Front. Ecol. Evol. 8:203.

doi: 10.3389/fevo.2020.00203

\section{Avian Egg Timers: Female Cowbirds Judge Past, Present, and Future When Making Nest Parasitism Decisions}

\author{
David J. White* \\ Department of Psychology, Wilfrid Laurier University, Waterloo, ON, Canada
}

The cognitive demands associated with brood parasitism are substantial. Not only must female parasites locate nests and assess their suitability for parasitism, they must also time parasitism to correspond with the breeding behavior of the host. Keeping track of the reproductive state of hosts for a variety of nests allows the parasite to select a nest where their egg can be incubated successfully. Thus, nest selection decisions are integral to obligate brood parasites' reproductive success. In captive breeding flocks of brown-headed cowbirds (Molothrus ater), I provided females access to mock nests that varied in the number of eggs present. By changing the number of eggs added to nests across days, I studied (1) females' abilities to time a host nest's readiness for parasitism and (2) the timing of females' nest selection decisions. I found that cowbirds can attend to the amount of time that elapsed since a host egg was added to a nest and can use that information to choose a nest for parasitism. Females made their choice of nest during prospecting the day before they laid, and, once decided, they did not update their decisions on the day of laying. Taken together, the results reveal that female cowbirds process substantial amounts of information about location, time, number, and rate in order to plan for future parasitism. This research program reveals that species-typical decisions integrate a variety of general and specialized cognitive abilities to allow females to behave adaptively and maximize reproductive success.

Keywords: cowbird, cognition, timing, nest parasitism, egg laying

\section{INTRODUCTION}

Understanding the animal mind has been of keen interest to researchers and laypeople for centuries (Dewsbury, 1989; Shettleworth, 2010). Research into how animals acquire, process and act on information has come in fits and starts across this time; there have been decades of tremendous interest and others of complete disregard. Currently, due to renewed interest from both biologists and psychologists working in the lab and field, and integrating function with the underlying mechanisms controlling decision processes, advances are being made in our understanding of animal cognition at a pace unmatched in the past (Bouton, 2007; Pearce, 2008).

Functional perspectives into cognition consider the information processing skills that animals possess to be specialized adaptations, evolved to deal with species-specific ecological demands (Sherry and Schacter, 1987). For example, the requirements to remember locations associated with 
habitats, mates, or stored food could lead to the evolution of enhanced spatial memory abilities (Sherry, 1982; Smulders et al., 2010), or the needs to navigate social hierarchies might produce new skills like transitive inference (Bond et al., 2003; Paz-y-Mino et al., 2004; Maclean et al., 2008). One of the critical implications of this perspective is that cognitive performance in real-world tasks is under selection pressure, and thus heritable variation in cognitive performance must relate in some manner to fitness. Thus, work under this perspective is often done examining species-typical behavior in the animals' natural habitat. And, while the connection between cognition and fitness is only starting to be discovered in some animal systems (see Sol et al., 2005; Cole et al., 2012; Cauchard et al., 2017; and other articles in this special issue) the evolutionary perspective provides a powerful organizing perspective.

Mechanistic perspectives approach animal cognition with less interest in ecology or evolution, and instead use a few animal species that are well suited for the laboratory as model systems for studying learning, behavior, perception, and action in order to shed light on universal aspects of cognition. Thus, even though both perspectives examine cognition, functional perspectives tend to focus on specializations while mechanistic perspectives tend to focus on domain-general processes (Heyes, 2012). These approaches need not be in conflict, however, it is possible for both specialized and general mechanisms to exist and interact. For example, there could be general aspects of problem-solving that can be coopted and enhanced by a specific ecological demand (Sherry and Schacter, 1987; Sherry, 2006). Tracking time, for example, is a general ability ubiquitous to animals, but for some species, certain ecological demands may enhance and specialize the ability to remember elapsed time or track it more precisely.

Another point of conflict between Psychologists and Biologists is methodological. Psychologists often explicitly avoided the examination of behaviors that relate to reproductive success. For example, the study of spatial memory in rodents is often measured using behavioral tests that are foreign to the activities of the animal, for example using computerized touch screens or water-mazes (Choi et al., 2006; Bussey et al., 2008). The argument against studying species-specific behavior found in the animal's repertoire is that such behavior might be under control of some sort of simple "instinctive" tendency, and thus such behavior is lacking in generalizability to other species (e.g., Domjan, 2010). It is, however, a mistake to think about speciesspecific behavior as simple instinctive reflexes. The biological validity of the instinct concept itself is severely limited (Lehrman, 1953), and merely because a behavior may be specific to a species does not therefore mean there is no underlying complexity in the cognitive processes that control it. Indeed, behaviors that relate directly to reproductive success would be most subject to selection, potentially leading to the evolution of complex levels of information processing.

My students and I have been studying the decision processes involved in selecting nests for parasitism by female brownheaded cowbirds (White, 2019). We use a procedure and a theoretical perspective that integrates both adaptationist and psychological perspectives to understand the cognitive abilities female cowbirds possess that allow them to select a viable nest in which to lay their eggs and for their young to develop to independence.

Finding and selecting a nest is critical for a parasite's reproductive success. Classic work has shown that female cowbirds have enhanced spatial memory skills compared to closely related non-brood parasites, or to conspecific males (Guigueno et al., 2015) and this is reflected in the neuroanatamy of hippocampus (Sherry et al., 1993), an area of the brain considered critical for spatial memory abilities. Beyond having the ability to find and remember the locations of nests, cowbirds are also sensitive to a remarkable number of features of hosts that relate to the chances that their offspring successfully fledge the nest. For example, cowbirds attend to the characteristics of the nest, the type and quality of the host, and the existing offspring (Clotfelter, 1998; Banks and Martin, 2001; Hauber, 2001; Grant and Sealy, 2002; Hauber et al., 2002; Hoover and Robinson, 2007; Louder et al., 2014, 2015; Swan et al., 2015).

Research from the wild, tracking individuals of closely related cowbird species, provides evidence that cowbirds are consistently monitoring nests over time to assess host defenses, host parenting abilities, and hosts' readiness for incubation (Fiorini and Reboreda, 2006; Gloag et al., 2013; Fiorini et al., 2014; Scardamaglia et al., 2016). Acquiring, prioritizing, and recalling this diverse information when selecting a nest can create a significant cognitive load and we have found natural variation among females in their ability to make these decisions effectively (Davies and White, 2018). Since these decisions relate directly to reproductive success, these cognitive abilities can be subject to selection pressure.

We study wild-caught cowbirds in large outdoor aviaries where they live and breed in patterns similar to the wild (Rothstein et al., 1986). These conditions allow us to examine female cowbirds' prospecting and egg-laying patterns while controlling information about the quality of nests. We do not provide actual hosts in our conditions but we have found that by manipulating the number, size, and visual characteristics of mock eggs in mock nests in the aviaries, we can change female cowbirds' nest selection preferences and manipulate the cognitive challenges associated with choosing the highest quality nest (White et al., 2007, 2009, 2017).

Our most frequently used manipulation involves changing the number of eggs in nests (White et al., 2007, 2009). We have found that cowbirds have distinct preferences for nests containing different numbers of eggs. Overall, all other factors being equal, females prefer nests containing more eggs to nests containing fewer eggs (at least in the range of 0-3 eggs; White et al., 2007). But much more important to females is whether nests change in egg number over time (White et al., 2009). Nests that increase in egg number from the day before are vastly preferred to nests that do not change from 1 day to the next. We have interpreted these findings as a mechanism that allows females to time their parasitism effectively, because hosts typically lay one egg each day until their entire clutch is laid. It is at that point that they commence incubation. Development starts with incubation and thus a nest where incubation has begun can be a bad place for a parasite's egg, as this late egg would be at a developmental disadvantage and could potentially not 
even hatch. Keeping track of the timing of egg laying by the host would be one means by which a cowbird could avoid the dangers associated with laying in a nest too late. To do so, however, requires the cowbird to attend to and process substantial amounts of information, including information about space, number, and time and using information about personal experiences to guide behavior, so-called what-where-when, or episodic-like memory (Clayton and Dickinson, 1998; Griffiths et al., 1999; Hampton and Schwartz, 2004).

Animals represent time in different ways, from evaluating very short timescales, to days, months and years (Gallistel, 1989; Dibner et al., 2010). We have conducted several studies in which we have given female cowbirds the opportunity to track nests that change or do not change across days (White et al., 2009). In these experiments, females preferred to inspect and preferred to lay in nests that changed in egg number corresponding to the number of days that had elapsed. We have never explicitly tested females' ability to track time in these experiments, however. Females could have performed these experiments merely by using numerical abilities and showing preferences for nests that change more than any other nest. In the first experiment here, I keep changes in egg number constant across nests and vary only the amount of time that had elapsed from one visit to another to assess whether females are indeed using time as part of parasitism decisions.

Not only is the timing of the hosts' reproductive behavior important, but it is also important for the cowbird to time her nest selection decision appropriately so that the host and parasite's reproduction are synchronized. Cowbirds typically lay at first light then spend the rest of the day investigating other nests (Friedmann, 1929). While we have found that the time females spend investigating a nest the day before laying relates to the likelihood of that female actually laying in the nest the next day (White et al., 2009, 2017; unpublished observations), it has not been explicitly tested whether females are actually choosing a nest on the prospecting day, or instead selecting a nest the morning of laying. If they are making the decision in advance in order to plan for their future egg laying (sensu Raby et al., 2007), then this is yet more information that must be processed when selecting a nest. Cowbirds may need to maintain a cognitive map of nest options at different stages of readiness so that they can respond selectively when ready to lay. In experiment 2 , I change nest characteristics at different times between the prospecting day and the egg laying day to determine the timing of the nest selection decision.

\section{MATERIALS AND METHODS}

\section{Experiment 1: Timing Host Behavior}

I examined whether female cowbirds were sensitive to the amount of time that has elapsed since they had examined a nest and whether they could use information about time and the number of host eggs encountered to select a nest for parasitism.

\section{Subjects}

Twelve wild-caught female cowbirds served as subjects for this experiment. These females were wild caught in Montgomery County PA as adults (i.e., they had experienced at least one breeding season in the wild in 2010-2011) and had been living in aviaries for at least 1 year prior to the experiment. Each female wore individually distinct combinations of colored leg bands to permit identification. Prior to experimentation, birds were housed with other females and with males in large outdoor $18 \times$ $6 \times 4 \mathrm{~m}$ aviaries.

For testing, birds were removed from their home aviary at the beginning of the breeding season (May 1-June 30, 2012) and housed in $4.26 \times 1.67 \times 2.13 \mathrm{~m}$ outdoor flight cages. The flight cages were divided into a holding area and a testing area by a wire mesh barrier (Figure 1). The test area could also be divided in half with a removable hardware cloth barrier which was used during the pretest phases (see below). The main dividing barrier between holding and test areas had two $12 \times 12 \mathrm{~cm}$ doors in the top corners that could be opened or closed externally from the cage to allow females to enter either side of the testing area.

The cage was outdoors. It had a grass floor and a variety of perches throughout. The holding area contained food, a roof shelter, and water. The test area also contained perches as well as two mock canary nests that contained grass and white Plaster of Paris mock eggs created from casts of cowbird eggs. Each egg had a plastic-coated paperclip affixed into its base so that it could be anchored into the nest and thus would not allow the cowbird to remove it. The number of eggs in the nests varied depending on experiment and day (see below). Nests were affixed to the side of the flight cage approximately 1 meter from the bottom of the cage. Each nest was covered such that females had to perch immediately in front of the nest and peer into it to examine the contents of the nest.

\section{Procedure}

Experiment 1a (see Table 1). Two days prior to the beginning of the experiment (Pretest day1), the door separating the holding area and one side of the test area was opened allowing a single female to enter. On this day, the female would find a nest containing two eggs. After 15 min elapsed from the time she first put her head into the opening of the nest, she was encouraged to fly back into the holding area and the door was closed. She remained in the holding area for the rest of the day. Only one female was housed in the flight cage for any given trial, but after

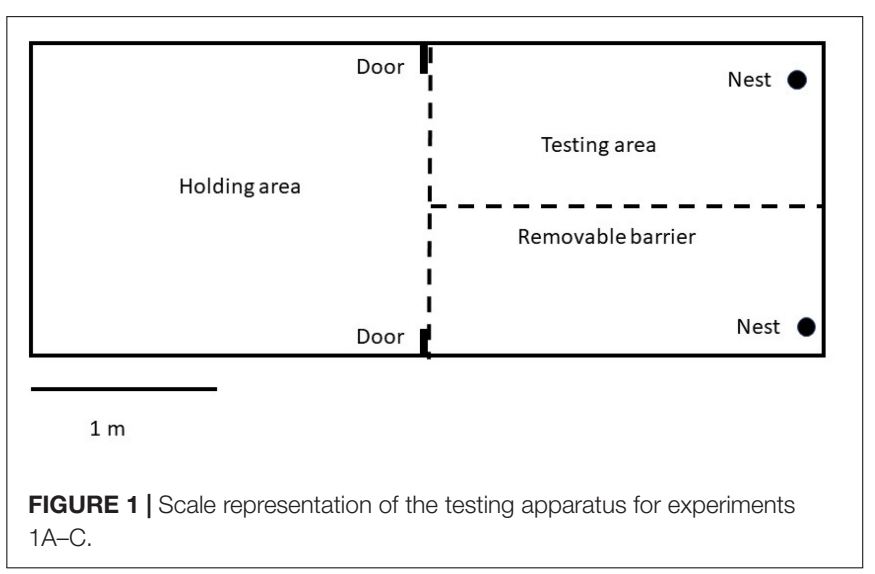


TABLE 1 | Outline of egg numbers in experimental manipulations.

\begin{tabular}{lllll}
\hline & \multicolumn{3}{c}{ Day } \\
\cline { 2 - 4 } & $\mathbf{1}$ & $\mathbf{2}$ & $\mathbf{3}$ & $\mathbf{4}$ \\
\hline Experiment 1A & 2 & 2 & 3 & 3 \\
Pretest 1 & & 3 & 3 \\
Pretest 2 & 0 & & & \\
Experiment 1B & & & & \\
Pretest 1 & & & & \\
Pretest 2 & & & & \\
Experiment 1C & & 2 & 3 & \\
Pretest 1 & 2 & & & \\
Pretest 2 & & & & \\
\hline
\end{tabular}

Numbers of eggs in each of the two nests in each of the 3 or 4 days of experiments $1 \mathrm{~A}-\mathrm{C}$. Bold indicates where there were significant preferences on the test day.

testing, groups of 6 females were housed together in the holding areas for the night.

The next day (Pretest day 2), she entered the other side of the testing area and encountered a nest also with two eggs in it. Again, after 15 min starting when she investigated one nest, she was returned to the holding area for the rest of the day.

On day 3 (Test day), she again could enter the testing area but now there was no barrier separating the two halves and she was given 15 min to spend time investigating the same two nests that she encountered on the two pretest days. During the test, however, both nests contained three eggs. Thus, both nests had increased by one egg, but the Pretest 1 nest increased by one egg with 2 days elapsing, whereas the Pretest 2 nest increased by one egg with only 1 day elapsing. I tested the 12 females in this experiment counterbalancing the sides they entered in the two pretest days. One female did not visit nests during the pretest days. She was removed from testing.

\section{Statistical Analysis}

I measured the amount of time females spent on the two nests on the test day. While it would be preferable to measure actual egg laying patterns from the subjects to definitively determine their preferences, female egg laying in these flight cages can be so unpredictable that it would be impossible to run the experiments in reasonable time. Fortunately, we have found in past experiments that the preference to spend time on a nest when prospecting reflects females' preference for laying in that nest (White et al., 2007, 2009, 2017; unpublished observations). Thus, we used time females spend on nests when prospecting as an assay of their preferences to lay in those nests. Time spent on the two nests were compared within-females using paired sample t-tests using SPSS software. All tests were two-tailed.

\section{Experiment 1b and 1c: Controlling for a Recency Bias}

I conducted two control experiments to assess whether females might be simply showing a preference for a nest they had visited more recently in the past. I used the same 12 females and the same apparatus in these two experiments with a similar procedure as the first experiment (see Table 1). In experiment 1b, females encountered an empty nest on Pretest day 1 and a two-egg nest on Pretest day 2. There was an extra delay day added between Pretest day 2 and the Test day during which females remained in the holding area. On the test day, females again encountered the two nests, and similar to experiment 1 , each nest contained three eggs. Thus, the nest from Pretest day 1 had increased by three eggs across 3 days and the nest seen on pretest day 2 increased by one egg across 2 days. If females were merely spending more time on the nest they had encountered more recently, then they should spend more time on the pretest day 2 nest. If, however, they were attending to the nest that had increased in egg number in the same ratio as days elapsed, then they should prefer the Pretest1 nest.

In experiment $1 c$, I kept the rate of change consistent across the two nests (see Table 1). The Pretest1 nest contained 2 eggs on day one, the Pretest 2 nest contained 2 eggs on day 2. One day elapsed before the Test day. On the Test day, females observed Pretest 1 nests now contained 4 eggs and Pretest 2 nests now contained 3 eggs. Thus, both nests increased by one egg per day since they had encountered them. If females preferred the nest they most recently encountered, they would prefer the pretest 2 nest. If they preferred nests with more eggs to fewer, they would prefer the Pretest1 nest, and if they preferred nests that changed commensurate with the number of days that had elapsed, then they should show no preference.

\section{Experiment 2. Timing of the Parasitism Decision}

The results of past work have revealed that female cowbirds are sensitive to the timing of eggs being laid by hosts (White et al., 2007, 2009). We have measured this both using females' prospecting patterns as well as their actual propensity to lay in nests in aviaries. We have never conclusively tested, however, whether females were actually making nest selection decisions during prospecting. Given that they would not be laying an egg until at least the next day, if they were making decisions on the prospecting day, they would be effectively planning for their future parasitism behavior. This form of 'mental time travel' represents an ability that many have considered to be an ability that few non-human animals possess (Tulving, 2002). An ability to do so nevertheless would suggest that part of the decision process females make involves a coordination between their own reproductive behavior and that of the hosts. Indeed, it would be difficult to account for the impressive abilities of female cowbirds in the wild to keep track of nests without such an ability (Fiorini and Reboreda, 2006; Gloag et al., 2013; Fiorini et al., 2014; Swan et al., 2015; Scardamaglia et al., 2016).

While we had never tested the timing of the parasitism decision in the past, some conundrums in egg laying patterns found over the years have suggested that the decision may indeed be made the day before laying. Two particular patterns have defied explanation until now. First, early in testing egg laying patterns in aviaries, I had not yet implemented the paperclip in the mock eggs to affix them into nests. It was often the case that in the mornings of egg collection, females would remove 
some of the mock eggs from the nests prior to other females laying. These other females, however, were still able to do the experiments effectively; they laid in the nests that followed their prospecting patterns from the day before. It was as if they were no longer sensitive to the number of eggs in nests on laying day.

Second, we had found that when nests are experimentally parasitized with a mock cowbird egg (a speckled egg added to a clutch of white eggs), females show very strong aversions to prospect or lay in the nests. When given a choice to lay in experimentally parasitized or non-parasitized nests, as many as 90\% of eggs were laid in non-parasitized nests (White et al., 2007). Cowbird young are very aggressive at begging for food and thus a nest already containing a cowbird baby would be a very competitive nest for another cowbird, thus it makes sense to avoid such a nest (Kilner et al., 2004). This aversion, however, is so strong, with so many females avoiding experimentally parasitized nests, that routinely multiple females in an aviary will lay in the same non-parasitized nests. While this makes sense for the first female, all subsequent females are effectively laying in alreadyparasitized nests. Again, it is as if females do not attend to the characteristics of the nests in the morning when laying.

In experiment 2, during the breeding season of 2013 (May 4-June 10), I made a number of manipulations to nests in aviaries at different times to document the time at which females made their nest selection decisions. To do so, I set out twelve nests in each of six outdoor aviaries containing six to eight adult female and six to eight male cowbirds in the breeding season. All nests contained three white mock eggs affixed with paperclips to the nests. In a series of manipulations across days I experimentally parasitized half of the nests ( $\mathrm{P}$ nests) in each aviary by removing one of the white eggs and replacing it with a speckled egg. To control for manipulating the nests, I removed a white egg from the non-parasitized nests (NonP nests) as well and replaced it with a new white egg. I varied the time at which I parasitized the nests such that females could examine the presence of the specked egg either during prospecting the day before laying, or only during the morning of laying. The different routines of experimental parasitism were as follows:

Trial 1: Parasitism occurred at 11:00 a.m. of the prospecting day (the day before egg collection).

Trial 2: Parasitism occurred at 11:00 p.m. of prospecting day (the night before egg collection).

Trial 3: Parasitism occurred at 11:00 a.m. of prospecting day. All eggs were then removed at 11:00 pm.

Trial 4: Parasitism occurred at 11:00 a.m. Parasitized eggs were then swapped at 11:00 p.m. such that the parasitized nests from the prospecting day became non-parasitized on the laying day and vice versa.

Trail 5: All nests were completely empty until 11:00 p.m., then half were filled as non-parasitized and half were filled as parasitized.

I collected all eggs laid in the aviaries between 5:30 and 7:00 a.m. each morning of the laying day and used the number of eggs laid in each type of nest as a measure of nest type preference for each of the trials. Because in each trial half the nests were experimentally parasitized and half were not, I calculated twotailed binomial probabilities for the number of eggs laid in Non parasitized nests based on a null hypothesis of $p=0.5$. Importantly if any nests were parasitized multiply, I only counted the first egg for data collection purposes because it was unclear whether other cowbird eggs in the nest in the morning would be a factor influencing subsequent females. There were too few cases of multiple parasitism over the course of this experiment (4 eggs total) to examine this question.

\section{RESULTS}

Experiment 1a: Females spent $1.77( \pm 0.65)$ min investigating the nest on Pretest day 1, and $1.62( \pm 0.39)$ min investigating the nest on Pretest day 2 [paired samples $t$-test $t(10)=0.25$, NS]. On the test day, females showed a significant preference to investigate the Pretest 2 nest (the nest that had increased by one egg after 1 day of delay) compared to the Pretest 1 nest (the nest that had increased by one egg after 2 days of delay). Mean min spent on Pretest1 nest: $1.12( \pm 0.32) \mathrm{min}$, Pretest2 nest: $2.30( \pm 0.53) \mathrm{min}$; paired samples $t(10)=3.16$, $P<0.01$ (Figure 2). This manipulation revealed that when females had information only about time elapsed (because equal numbers of eggs were added to two nests) they selected the nest where the number of eggs added corresponded to the number of days that had elapsed since prospecting. This result is consistent with experiments where we kept time consistent but changed the number of eggs encountered in the nests (White et al., 2009).

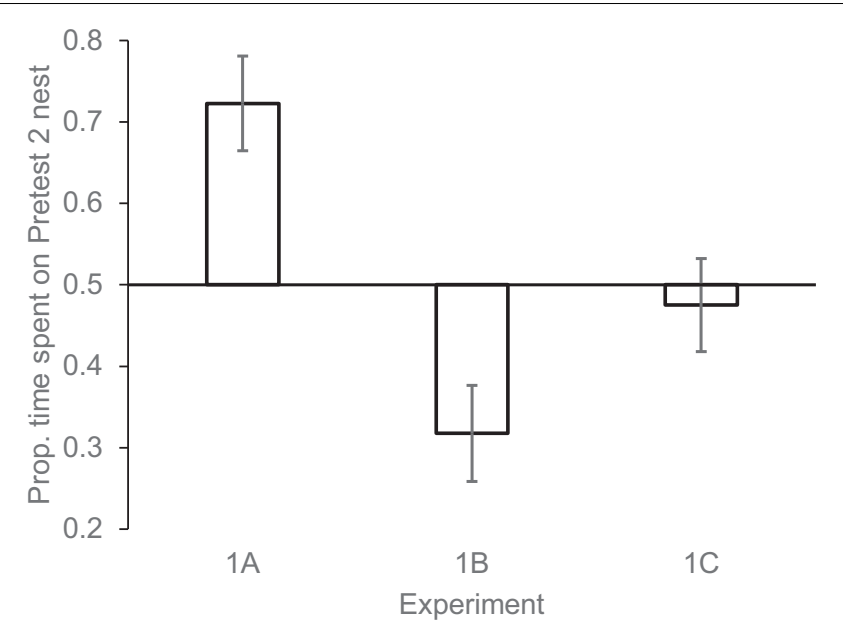

FIGURE 2 | Mean ( \pm 1 SEM) proportion of nest visiting time females spent investigating the Pretest2 nest (the nest encountered on the second pretest day) in each of the three phases of experiment 1. Experiment 1A: Pretest2 nest had higher rate of change (eggs being added across days) than the Pretest1 nest. Experiment 1B: the Pretest1 nest had a higher rate of change than the Pretest2 nest. Experiment 1C: The two nests changed at equal rates. $N=11$ females, in $1 \mathrm{~A}, 9$ females in $1 \mathrm{~B}, 12$ females in $1 \mathrm{C}$. 
Experiment 1b: Three females failed to investigate at least one nest during the pretest phase. They were removed from testing. Females spent $1.13( \pm 0.11)$ min investigating the Pretest 1 nest and $1.27( \pm 0.71)$ min investigating the Pretest 2 nest during the pretest phases (paired samples $t$-test $t(8)=0.34$, NS) .

On the Test day, females spent significantly more time on Pretest 1 nest compared to the nest that had more recently been investigated (Pretest2). Mean min spent on Pretest1 nest: 1.64 $( \pm 0.31) \mathrm{min}$, Pretest 2 nest: $0.91( \pm 0.33) \mathrm{min}$; paired samples $t(8)=2.55, P<0.05$ (Figure 2).

Experiment 1c: All females investigated nests in this experiment. They spent $1.01( \pm 0.09) \mathrm{min}$ investigating the Pretest 1 nest, and $0.94( \pm 0.14)$ min investigating the pretest 2 nest during pretest days [paired samples $t$-test $t(11)=0.12, \mathrm{NS}]$.

On the Test day, females did not show a significant preference to spend more time on one nest vs. the other. Mean time spent on Pretest1 nest: $1.52( \pm 0.32)$ min, Pretest 2 nest: $1.39( \pm 0.31)$ min; paired samples $t$-test $t(11)=0.52$, NS (Figure 2). The two control experiments revealed that females preferred nests where the same number of eggs had been added as days had elapsed since their first visit and showed no strong preference for a nest if both nests had changed in egg numbers from their last visit. These conditions demonstrated that the effect in experiment la was not a function of a recency bias in nest encounters from past days.

\section{Experiment 2}

Trial 1: Females showed a strong aversion to lay in experimentally parasitized nests when the speckled egg was added in the morning of the prospecting day. Eggs laid in NonP nests/total eggs $=16 / 18$, Binomial test probability, $p=0.002$ (Figure 3).

Trial 2: When experimental parasitism occurred at night and thus there was no opportunity to see where parasitism occurred prior to the laying day, females showed no aversion to lay in parasitized nests: Eggs laid in NonP nests/total eggs $=13 / 23$ Binomial test probability, $p=0.678$.

Trial 3: When nests were emptied at night such that there was information gained during prospecting day, but no egg information present on laying day, females laid in the nests that were NonP on prospecting day. Eggs laid in NonP nests/total eggs $=11 / 13$, Binomial test probability, $p=0.022$.

Trial 4: When the nests that were parasitized on prospecting day were reversed at night, such that they became non-parasitized on laying day, females showed an aversion to the nests that had been parasitized on prospecting day, not the nests parasitized on laying day. Eggs laid in NonP (laying day)/total eggs $=4 / 18$. Binomial test probability, $p=0.031$.

Trial 5: When nests were empty until the night of prospecting day, and then half the nests were parasitized for laying day, females showed no aversion to the parasitized nests. Eggs laid in NonP nests/total eggs $=6 / 10$. Binomial test probability, $p=0.754$. Taken together, this series of trials reveals strong evidence to suggest that the nest selection decision is made the day before laying and is remarkably resistant to change afterward; even when there is conflicting (Trial 4), or no valuable information (Trial 5)

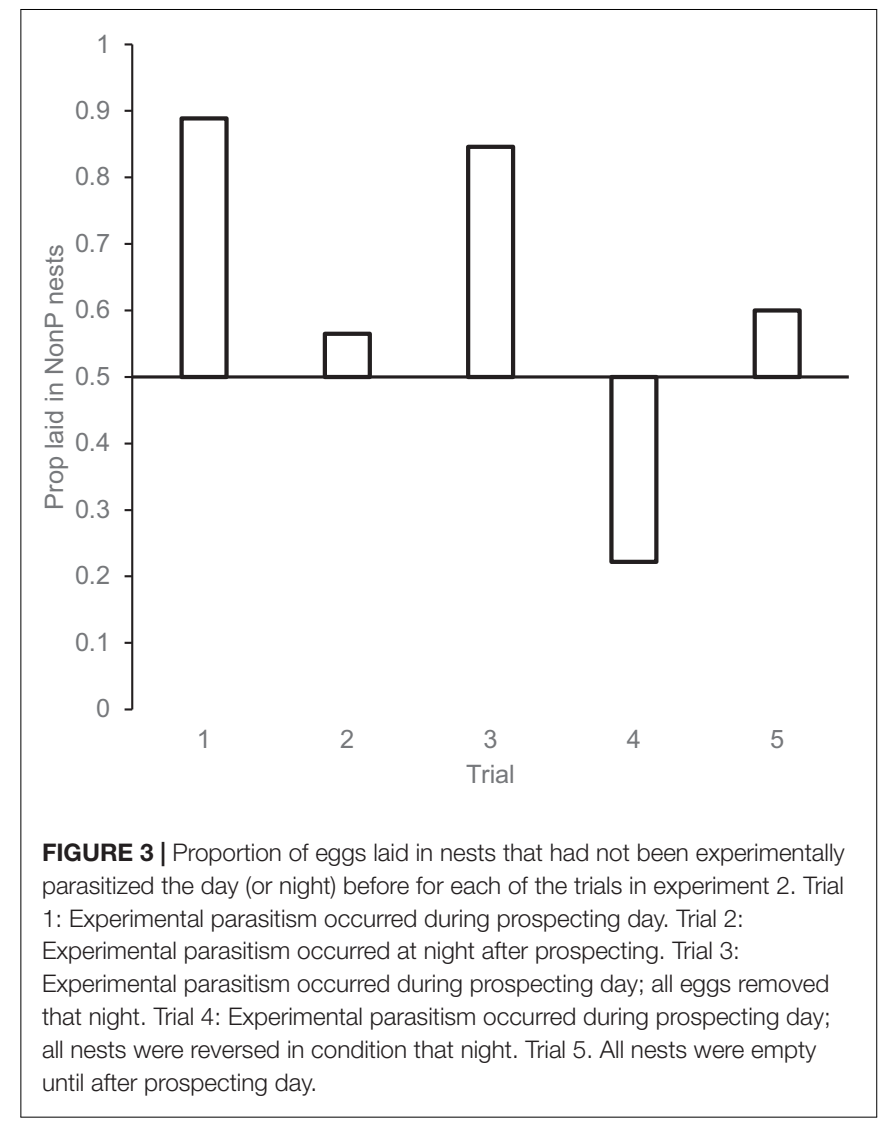

on prospecting day. Females do not use information from laying day to inform their nest selection decisions.

\section{DISCUSSION}

The results of these experiments provide two new insights into the nest prospecting decision processes of female brownheaded cowbirds. First, females have an ability to track time elapsed between nest visits and use this information in concert with numerical information- egg number changesto measure the rate of eggs added to nests. They then can compare rates of change across nests to select the nest where the rate of eggs added corresponds with, or at least is not less than, the number of days that had elapsed since first encountering the nests. Second, experiment 2 reveals compelling evidence that females are assessing nests and deciding on the nest best suited for parasitism during the prospecting day prior to egg laying. They are, in effect planning for the future (Suddendorf and Corballis, 1997; Raby et al., 2007).

\section{Timing Hosts}

We have found very reliable effects across numerous experiments showing female cowbirds track how nests change in egg number across time as a cue to select a nest for parasitism (White et al., 2007, 2009, 2017). The current experiments for the first 
time directly reveal that cowbirds use the time elapsed between nest visits to assess rates of egg laying. Prior to this work, a simpler mechanism could have accounted for the effects involving females selecting nests where the most eggs were added. This hypothesis is refuted by experiment 1 , where both nests increased by the same amount but not at the same rate. The patterns in experiment one could not be explained by a simpler mechanism of just preferring the most recently encountered nest (see also White et al., 2009), though the possibility remains that females use a variety of different decision heuristics such that they weigh different types of information in each circumstance in which I placed them.

These findings provide numerous possibilities for future study of both the functional and mechanistic processes involved in the cognitive processes of timing. From the functional perspective, the cognitive demands associated with tracking the rates of change of eggs in numerous nests, in the wild, comparing among them, integrating this information with the other important characteristics of hosts and nests all to choose one nest would be a remarkable cognitive load. The relationship between variation in these abilities and reproductive success is currently under study (Davies and White, 2018). These patterns seen in the lab with numerous variables controlled and removed, do fit with findings in the wild where cowbirds of closely related species consistently visit nests to synchronize breeding patterns with hosts (Fiorini and Reboreda, 2006; Swan et al., 2015).

From a mechanistic perspective, it could be that tracking time, space, and number - aspects of cognition ubiquitous to animals that are essential in a wide variety of contexts (Davis and Perusse, 1988; Gallistel, 1989; Clayton and Dickinson, 1998; Brannon, 2006) may be specialized in cowbirds, allowing them to be more sensitive to representations of time and number or to remember them longer. How they keep track of the amount of time elapsed is an important future question, as it does seem the delays they could deal with in experiments 1 and 2 are longer than what most animals can attend and remember in lab-based delay interval experiments (Domjan, 2010). This offers many labbased possibilities for testing stimulus control of behavior and to investigate the underlying neural processes that may govern these abilities.

\section{Timing of Decisions}

Results of experiment 2 suggest that information acquired and processed about nests during prospecting time is fundamentally different than during laying time. Females appeared incapable of updating their decision processes in the morning of egg laying, even when information was lacking during prospecting. Cowbirds lay at first light and can enter a nest and lay an egg in as little as one second. Perhaps the demands associated with cryptically getting in and depositing their egg so quickly is so important (Friedmann, 1963), selection actually favors ignoring nest contents when laying. This is another pattern of prospecting that appears in the wild in closely related cowbird species (Scardamaglia et al., 2016).

We are now using radio frequency identification on nests in order to investigate every prospecting event females make so that we can track in real time how they investigate nests, whether different females use different strategies, whether females who are going to lay the next day prospect differently than females who are not going to lay that day, and whether highly fecund females prospect differently than less fecund females.

\section{Ecology and Evolution of Cognition}

Taken together, these experiments on the decision processes associated with nest selection provide an integration of biological and psychological traditions. We study a species-specific natural behavior that requires no training or reinforcement and is directly connected to reproductive success. While we do still use a laboratory environment for testing, and it necessarily removes a wide variety of the important variables that are undoubtedly important in the cowbirds' nests selection decisions (most notably the behavior of hosts), we do provide them the stimuli necessary to court, breed and lay eggs. This allows us to maintain a high degree of control over stimulus presentations and prior experiences. This approach has provided us insights into many different aspects of the form and function of cognition in nature.

\section{DATA AVAILABILITY STATEMENT}

The datasets generated for this study are available on request to the corresponding author.

\section{ETHICS STATEMENT}

The animal study was reviewed and approved by the Institutional Animal Care and Use Committee of the University of Pennsylvania (\#800439), and the Animal Care Committee of Wilfrid Laurier University (\#17000).

\section{AUTHOR CONTRIBUTIONS}

DW conducted all research and wrote the manuscript.

\section{FUNDING}

This work was supported by the Natural Sciences and Engineering Research Council of Canada and the National Science Foundation of the USA. All work was done under the University of Pennsylvania Institutional Animal Use and Care guidelines (\#800439).

\section{ACKNOWLEDGMENTS}

Lucy Ho and Grace Freed-Brown assisted in egg collection. Laure Cauchard and three reviewers provided valuable comments on an earlier version of the manuscript. 


\section{REFERENCES}

Banks, A. J., and Martin, T. E. (2001). Host activity and the risk of nest parasitism by brown-headed cowbirds. Behav. Ecol. 12, 31-40. doi: 10.1093/oxfordjournals. beheco.a000375

Bond, A. B., Kamil, A. C., and Balda, R. P. (2003). Social complexity and transitive inference in corvids. Anim. Behav. 65, 479-487. doi: 10.1006/anbe.2003.2101

Bouton, M. E. (2007). Learning and Behavior: A Contemporary Synthesis. Sunderland, MA: Sinauer.

Brannon, E. M. (2006). The representation of numerical magnitude. Curr. Opin. Neurobiol. 16, 222-229. doi: 10.1016/j.conb.2006.03.002

Bussey, T. J., Padain, T. L., Skillings, E. A., Winters, B. D., Morton, J., and Saksida, L. M. (2008). The touchscreen cognitive testing method for rodents: how to get the best out of your rat. Learn. Mem. 15, 516-523. doi: 10.1101/lm.987808

Cauchard, L., Angers, B., Boogert, N. J., Lenarth, M., Bize, P., and Doligez, B. (2017). An experimental test of a causal link between problem-solving performance and reproductive success in wild great tits. Front. Ecol. Evol. 5:107. doi: 10.3389/fevo.2017.00107

Choi, S. H., Woodlee, M. T., Hong, J. J., and Schallert, T. (2006). A simple modification of the water maze test to enhance daily detection of spatial memory in rats and mice. J. Neurosci. Methods 156, 182-193. doi: 10.1016/j. jneumeth.2006.03.002

Clayton, N. S., and Dickinson, A. (1998). Episodic-like memory during cache recovery by scrub jays. Nature 395, 272-274. doi: 10.1038/26216

Clotfelter, E. D. (1998). What cues do brown-headed cowbirds use to locate redwinged blackbird host nests? Anim. Behav. 55, 1181-1189. doi: 10.1006/anbe. 1997.0638

Cole, E. F., Morand-Ferron, J., Hinks, A. E., and Quinn, J. L. (2012). Cognitive ability influences reproductive life history variation in the wild. Curr. Biol. 22, 1808-1812. doi: 10.1016/j.cub.2012.07.051

Davies, H. B., and White, D. J. (2018). Specializations in cognition generalize across contexts: cowbirds are consistent in nest prospecting and foraging tasks. Anim. Behav. 144, 1-7. doi: 10.1016/j.anbehav.2018.07.019

Davis, H., and Perusse, R. (1988). Numerical competence in animals: definitional issues, current evidence, and a new research agenda. Behav. Brain Sci. 11, 561-579. doi: 10.1017/s0140525x00053437

Dewsbury, D. A. (1989). Comparative psychology, ethology and animal behavior. Annu. Rev. Psychol. 40, 581-602. doi: 10.1146/annurev.ps.40.020189.003053

Dibner, C., Schibler, U., and Albrecht, U. (2010). The mammalian circadian timing system: organization and coordination of central and peripheral clocks. Annu. Rev. Physiol. 72, 517-549. doi: 10.1146/annurev-physiol-021909-135821

Domjan, M. (2010). The Principles of Learning and Behavior. Belmont, CA: Wadsworth

Fiorini, V. D., Gloag, R., Kacelnik, A., and Reboreda, J. C. (2014). Strategic egg destruction by brood-parasitic cowbirds? Anim. Behav. 93, 225-235.

Fiorini, V. D., and Reboreda, J. C. (2006). Cues used by shiny cowbirds (Molothrus bonariensis) to locate and parasitise chalk-browed mockingbird (Mimus saturninus) nests. Behav. Ecol. Sociobiol. 60, 379-385. doi: 10.1007/ s00265-006-0175-3

Friedmann, H. (1929). The Cowbirds: A study in the Biology of Social Parasitism. Springfield, IL: C. C. Thomas.

Friedmann, H. (1963). Host Relations of the Parasitic Cowbirds. Washington, DC: Smithsonian Institution.

Gallistel, C. R. (1989). Animal cognition: the representation of space, time, and number. Annu. Rev. Psychol. 40, 155-189. doi: 10.1146/annurev.ps.40.020189. 001103

Gloag, R., Fiorini, V. D., Reboreda, J. C., and Kacelnik, A. (2013). The wages of violence: mobbing by mockingbirds as a frontline defence against broodparasitic cowbirds. Anim. Behav. 86, 1023-1029. doi: 10.1016/j.anbehav.2013. 09.007

Grant, N. D., and Sealy, S. G. (2002). Selection of red-winged blackbird (Agelaius phoeniceus) hosts by the brown-headed cowbird (Molothrus ater). Bird Behav. $15,21-30$.

Griffiths, D., Dickinson, A., and Clayton, N. (1999). Episodic memory: what can animals remember about their past? Trends Cogn. Sci. 3, 74-80. doi: 10.1016/ S1364-6613(98)01272-8 doi: 10.1016/s1364-6613(98)01272-8

Guigueno, M. F., MacDougall-Shackleton, S. A., and Sherry, D. F. (2015). Sex differences in spatial memory in brown-headed cowbirds: males outperform females on a touchscreen task. PLoS One 10:e0128302. doi: 10.1371/journal. pone. 0128302

Hampton, R. R., and Schwartz, B. L. (2004). Episodic memory in nonhumans: what, and where, is when? Curr. Opin. Neurobiol. 14, 192-197. doi: 10.1016/j.conb. 2004.03.006

Hauber, M. E. (2001). Site selection and repeatability in Brown-headed cowbird (Molothrus ater) parasitism of Eastern Phoebe (Sayornis phoebe) nests. Can. J. Zool. Rev. Can. Zool. 79, 1518-1523. doi: 10.1139/z01-091

Hauber, M. E., Pearson, H. E., Reh, A., and Merges, A. (2002). Discrimination between host songs by brood parasitic brown-headed cowbirds (Molothrus ater). Anim. Cogn. 5, 129-137. doi: 10.1007/s10071-002-0143-x

Heyes, C. (2012). Simple minds: a qualified defence of associative learning. Philos. Trans. R. Soc. Lond. B 367, 2695-2703. doi: 10.1098/rstb.2012. 0217

Hoover, J. P., and Robinson, S. K. (2007). Retaliatory mafia behavior by a parasitic cowbird favors host acceptance of parasitic eggs. Proc. Natl. Acad. Sci. U.S.A. 104, 4479-4483. doi: 10.1073/pnas.0609710104

Kilner, R. M., Madden, J. R., and Hauber, M. E. (2004). Brood parasitic cowbird nestlings use host young to procure resources. Science 305, 877-879. doi: $10.1126 /$ science. 1098487

Lehrman, D. S. (1953). A critique of Konrad Lorenz's theory of instinctive behavior. Q. Rev. Biol. 28, 337-363. doi: 10.1086/399858

Louder, M. I. M., Schelsky, W. M., Albores, A. N., and Hoover, J. P. (2015). A generalist brood parasite modifies use of a host in response to reproductive success. Proc. B 282:1615.

Louder, M. I. M., Schelsky, W. M., Benson, T. J., and Hoover, J. P. (2014). Brownheaded cowbirds exploit a host's compensatory behavioral response to fecundity reduction. Behav. Ecol. 26, 255-261. doi: 10.1093/beheco/aru187

Maclean, E. L., Merritt, D. J., and Brannon, E. M. (2008). Social complexity predicts transitive reasoning in prosimian primates. Anim. Behav. 76, 479-486. doi: 10.1016/j.anbehav.2008.01.025

Paz-y-Mino, G. C., Bond, A. B., Kamil, A. C., and Balda, R. P. (2004). Pinyon jays use transitive inference to predict social dominance. Nature 430, 778-781. doi: $10.1038 /$ nature 02723

Pearce, J. M. (2008). Animal Learning and Cognition: An Introduction. New York, NY: Psychology Press.

Raby, C. R., Alexis, D. M., Dickinson, A., and Clayton, N. (2007). Planning for the future by western scrub-jays. Nature 445, 919-921. doi: 10.1038/nature 05575

Rothstein, S. I., Yokel, D. A., and Fleischer, R. C. (1986). Social dominance, mating and spacing systems, female fecundity, and vocal dialects in captive and freeranging brown-headed cowbirds. Curr. Ornithol. 3, 127-185. doi: 10.1007/9781-4615-6784-4 3

Scardamaglia, R., Fiorini, V. D., Kacelnik, A., and Reboreda, J. C. (2016). Planning host exploitation through prospecting visits by parasitic cowbirds. Behav. Ecol. Sociobiol. 71:23. doi: 10.1007/s00265-016-2250-2258

Sherry, D. F. (1982). Food storage, memory, and marsh tits. Anim. Behav. 30, 631-633. doi: 10.1016/s0003-3472(82)80080-8

Sherry, D. F. (2006). Neuroecology. Annu. Rev. Psychol. 57, 167-197.

Sherry, D. F., Forbes, M. R., Khurgel, M., and Ivy, G. O. (1993). Females have a larger hippocampus than males in the brood-parasitic brown-headed cowbird. Proc. Natl. Acad. Sci. U.S.A. 90, 7839-7843. doi: 10.1073/pnas.90.16.7839

Sherry, D. F., and Schacter, D. L. (1987). The evolution of multiple memory systems. Psychol. Rev. 94, 439-454. doi: 10.1037/0033-295x.94.4.439

Shettleworth, S. J. (2010). Cognition, Evolution, and Behavior, 2nd Edn. New York, NY: Oxford Press.

Smulders, T. V., Gould, K. A., and Leaver, L. A. (2010). Using ecology to guide the study of cognitive and neural mechanisms of different aspects of spatial memory in food-hoarding animals. Philos. Trans. R. Soc. Lond. B 365, 883-900. doi: 10.1098/rstb.2009.0211

Sol, D., Duncan, R. P., Blackburn, T. M., Cassey, P., and Lefebvre, L. (2005). Big brains, enhanced cognition, and response of birds to novel environments. Proc. Natl. Acad. Sci. U.S.A. 102, 5460-5465. doi: 10.1073/pnas.0408145102

Suddendorf, T., and Corballis, M. C. (1997). Mental time travel in animals? Trends Cogn. Sci. 7, 133-167.

Swan, D. C., Zanette, L. Y., and Clinchy, M. (2015). Brood parasites manipulate their hosts: experimental evidence for the farming hypothesis. Anim. Behav. 105, 29-35. doi: 10.1016/j.anbehav.2015.03.012 
Tulving, E. (2002). Episodic memory, from mind to brain. Annu. Rev. Psychol. 53, 1-25. doi: 10.1146/annurev.psych.53.100901. 135114

White, D. J. (2019). Cowbird cognition: examinations of the mental skills of a brood parasite. Adv. Study Behav. 51, 144-177.

White, D. J., Davies, H. B., Agyapong, S., and Seegmiller, N. (2017). Nest prospecting brown-headed cowbirds 'parasitize' social information when the value of personal information is lacking. Proc. R. Soc. B Biol. Sci. 284, 1-8.

White, D. J., Ho, L., de los Santos, G., and Godoy, I. (2007). An experimental test of preferences for nest contents in an obligate brood parasite, Molothrus ater. Behav. Ecol. 18, 922-928. doi: 10.1093/beheco/arm062

White, D. J., Ho, L., and Freed-Brown, G. (2009). Counting chicks before they hatch: female cowbirds can time readiness of a host nest for parasitism. Psychol. Sci. 20, 1140-1145. doi: 10.1111/j.1467-9280.2009. 02418.x

Conflict of Interest: The author declares that the research was conducted in the absence of any commercial or financial relationships that could be construed as a potential conflict of interest.

Copyright (c) 2020 White. This is an open-access article distributed under the terms of the Creative Commons Attribution License (CC BY). The use, distribution or reproduction in other forums is permitted, provided the original author(s) and the copyright owner(s) are credited and that the original publication in this journal is cited, in accordance with accepted academic practice. No use, distribution or reproduction is permitted which does not comply with these terms. 